\title{
Supplement
}

\section{Interaction of Skatole and Androstenone in the Olfactory Perception of Boar Taint}

Daniel Mörlein ${ }^{1,6}$, Johanna Trautmann ${ }^{1}$, Jan Gertheiss ${ }^{1,7}$, Lisa Meier-Dinkel ${ }^{1}$, Jochen Fischer $^{3}$, Hans-Jörg Eynck ${ }^{4}$, Lourens Heres ${ }^{5}$, Christian Looft ${ }^{2,8}$, Ernst Tholen ${ }^{2}$

${ }^{1}$ University of Goettingen, Department of Animal Sciences, Albrecht-Thaer-Weg 3, 37075 Göttingen, Germany

${ }^{2}$ University of Bonn, Institute of Animal Science, University of Bonn, D-53115 Bonn, Germany

${ }^{3}$ ELFI Analytik GbR, Massenhausener Straße 18a, 85375 Neufahrn

${ }^{4}$ Tönnies Lebensmittel GmbH \& Co. KG, In der Mark 2, 33378 Rheda-Wiedenbrück, Germany

${ }^{5}$ Vion Food Group, Boseind 10, 5280 AA Boxtel, The Netherlands

${ }^{6}$ isi $\mathrm{GmbH}$ (present address)

${ }^{7}$ Clausthal University of Technology, Institute of Applied Stochastics and Operations Research, Erzstraße 1, 38678 Clausthal-Zellerfeld, Germany (present address)

${ }^{8}$ University of Applied Sciences, Brodaer Straße 2, 17033 Neubrandenburg, Germany (present address)

>> in memoriam Prof. Dr. Michael Wicke $\left({ }^{*} 24.6 .1959+2.7 .2015\right)<<$ 


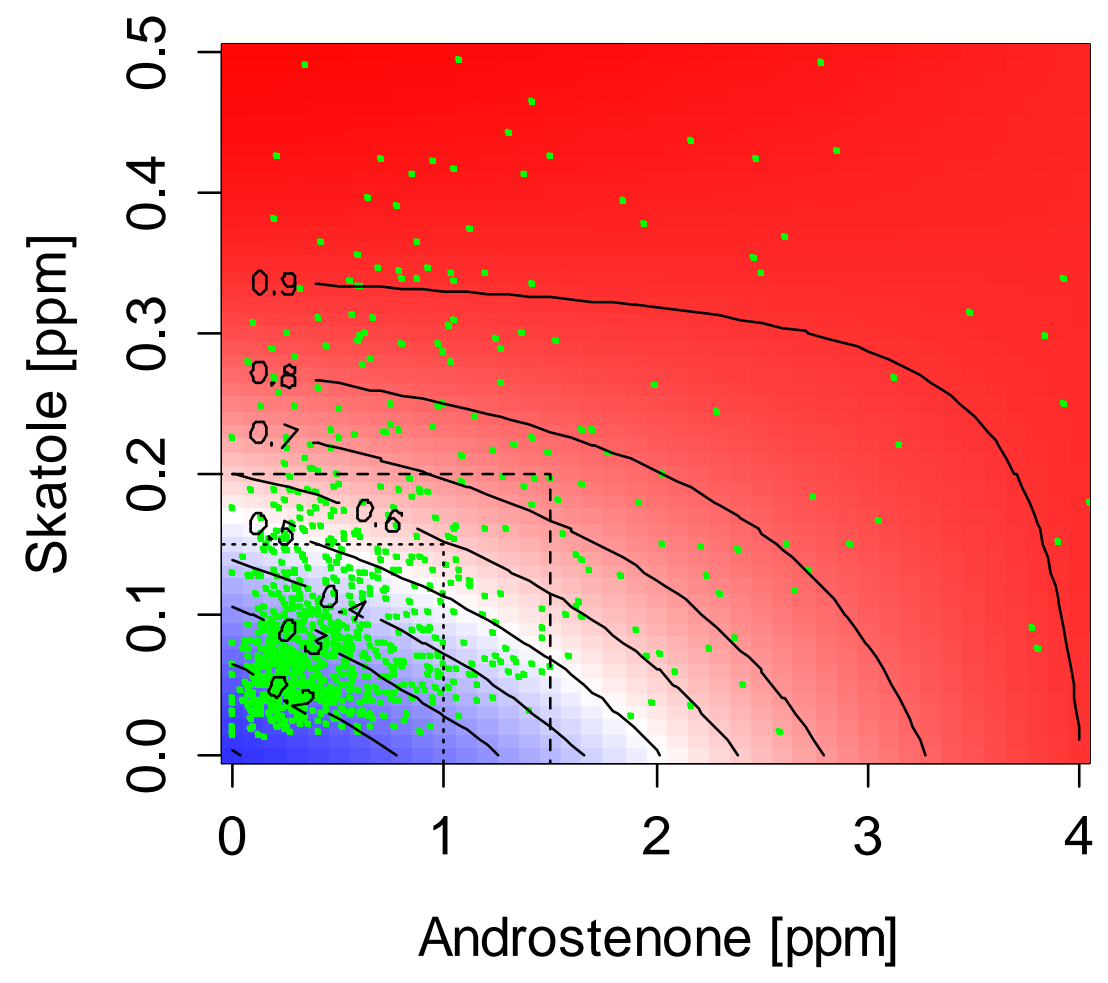

Supplement Figure 1: Predicted sensory perception using androstenone and skatole levels. Here, mean panel scores were dichotomized: panel average [0 2[ = "untainted", [2 5] = "boar tainted". The dotted line marks the "safe box" when using strict thresholds ( $1.0 \mathrm{ppm}$ androstenone, $0.15 \mathrm{ppm}$ skatole) whereas the dashed line illustrates the more liberal thresholds ( $1.5 \mathrm{ppm}$ androstenone, $0.2 \mathrm{ppm}$ skatole). Dots represent the chemical values of the samples used for the modelling. 
Supplement Table 1: Parameters of the model for prediction of dichotomized panel mean score using androstenone and skatole levels (Supplement Figure 1). Here, mean panel scores $<2$ were regarded as "untainted", panel mean scores $\geq 2$ as "boar tainted".

\begin{tabular}{cccccc}
\hline & Estimate & S.E. & z value & $\operatorname{Pr}(>|z|)$ & \\
\hline (Intercept) & -2.2344 & 0.1607 & -13.908 & $<.001$ & $* * *$ \\
Androstenon & 1.1058 & 0.1531 & 7.222 & $<.001$ & $* * *$ \\
Skatol & 13.1713 & 1.3448 & 9.794 & $<.001$ & $* * *$ \\
Androstenon x Skatol & -3.0979 & 0.4967 & -6.237 & $<.001$ & $* * *$ \\
\hline
\end{tabular}



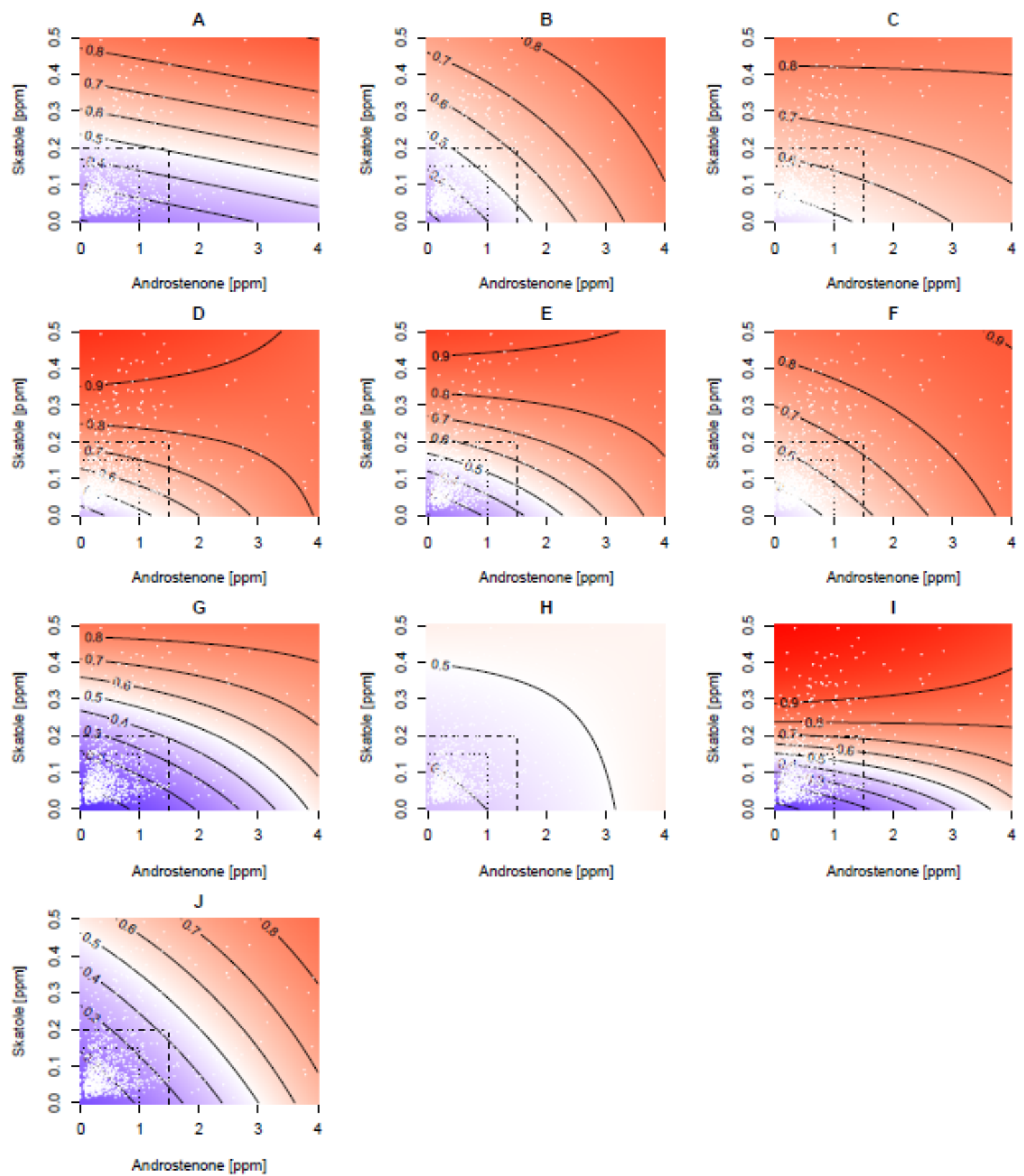

Supplement Figure 2: Predicted sensory perception for individual assessors (A to J) using a generalized linear regression model including androstenone and skatole levels as well as their interaction (model 1 ). Original ratings (from $0=$ standard to $5=$ strong deviation from standard) were dichotomized (untainted: scores $<2$, else tainted). The dotted line marks the "safe box" when using strict thresholds (1.0 ppm androstenone, $0.15 \mathrm{ppm}$ skatole) whereas the dashed line illustrates the more liberal thresholds (1.5 ppm androstenone, $0.2 \mathrm{ppm}$ skatole). 


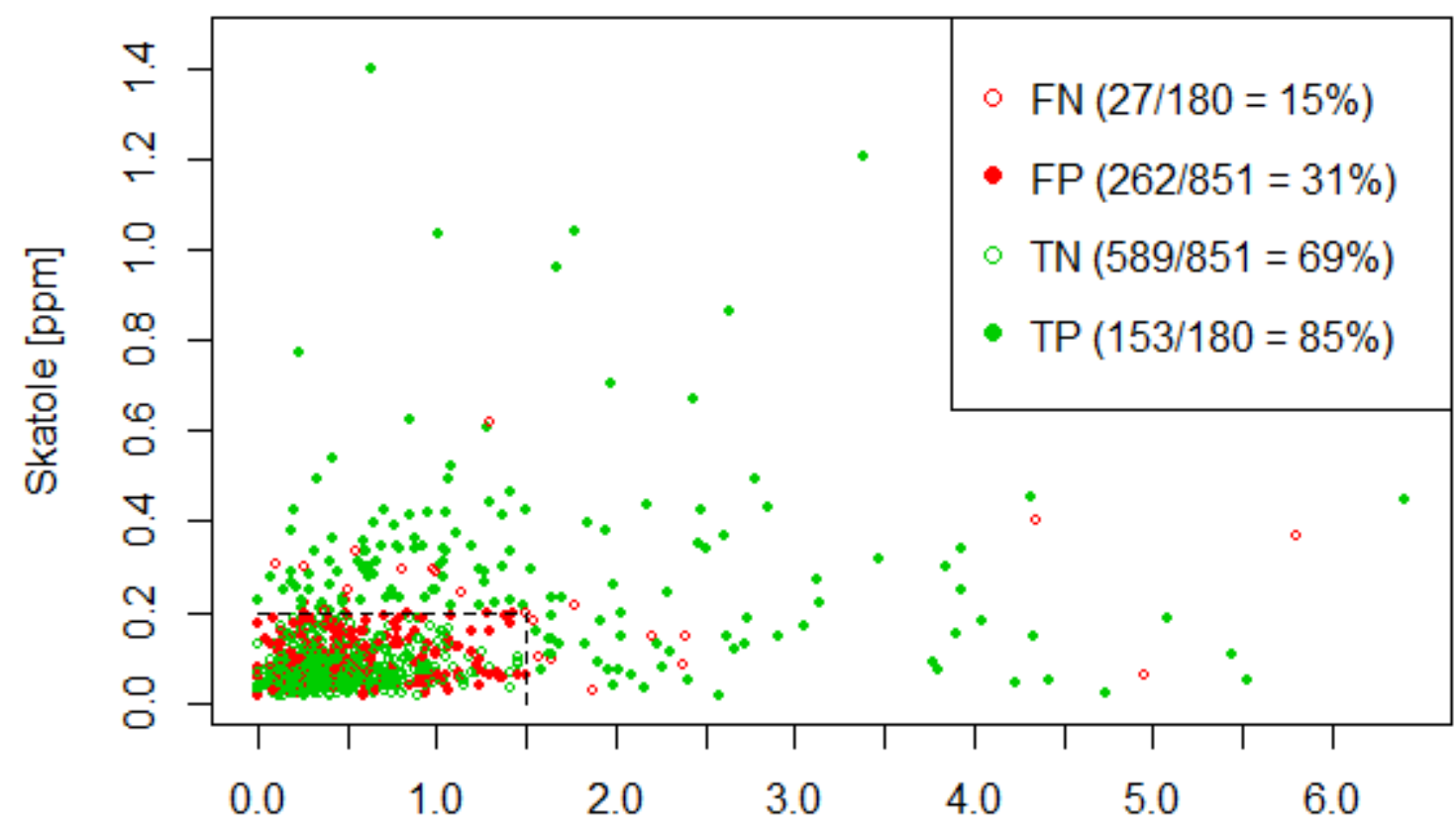

Androstenone [ppm]

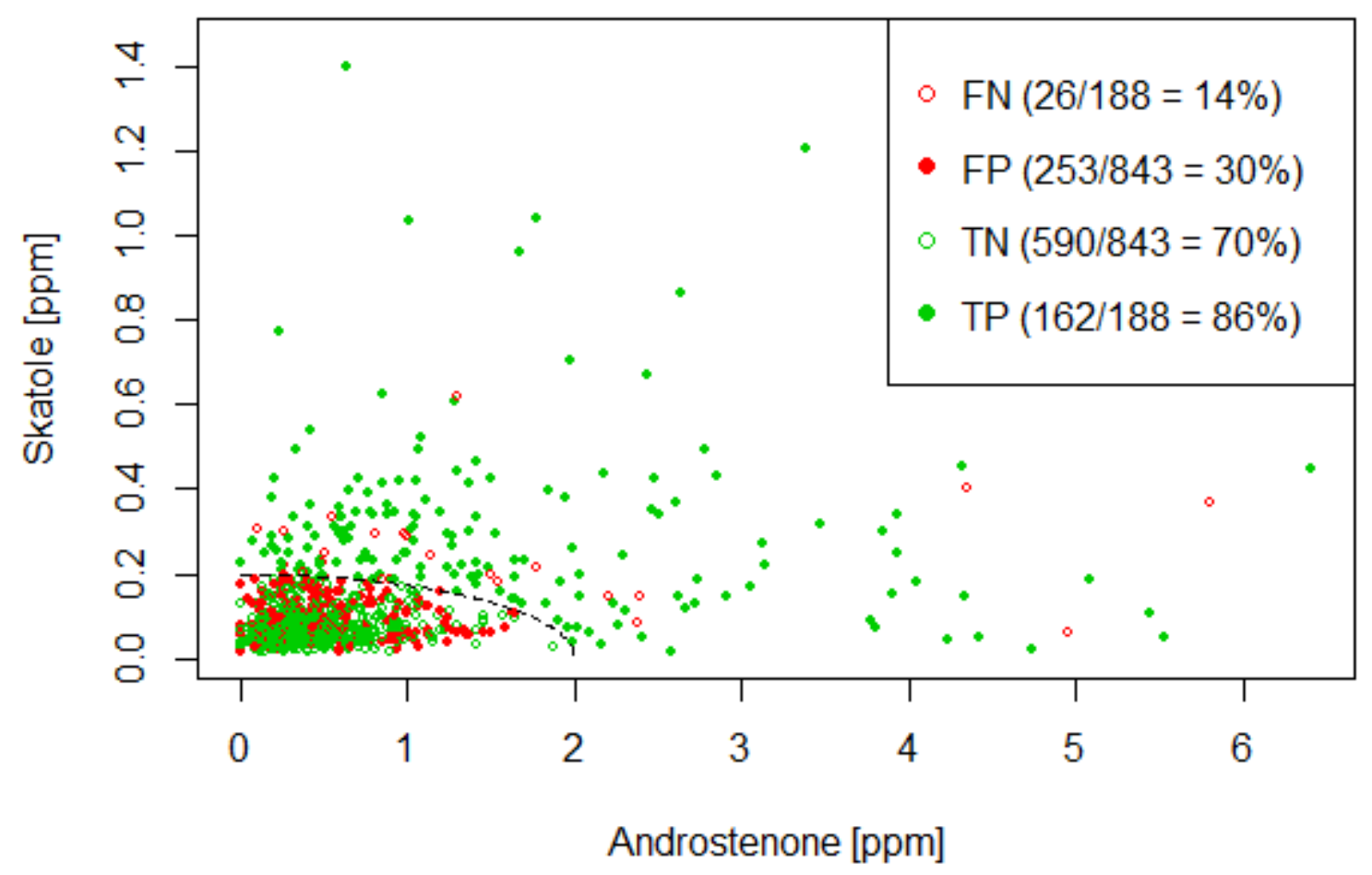

Supplement Figure 3: Comparison of sensory ratings with chemical analysis as 'Golden standard' for boar taint classification. Sensory classification of tainted samples is based on panel average $\geq 2$. Upper panel: "safe box" approach using thresholds for androstenone (1.5 ppm) and skatole (0.2 ppm). Lower panel: curved approach using thresholds for androstenone $\theta_{A N}=2.0 \mathrm{ppm}$ and $\theta_{S K}=0.2 \mathrm{ppm}$, and $q=2$. 
Supplement Table 2. Performance of single sensory assessors as compared to the panel average $(\varnothing)$ considering the chemical analysis as golden standard ("safe box" approach). A sample was considered as truly tainted if thresholds for androstenone (1.5 ppm) or skatole $(0.2 \mathrm{ppm})$ were exceeded. A sample was classified as deviant if the sensory score was equal or greater than 2 (scale from $0=$ standard pork fat odor to $5=$ strong deviation from standard).

\begin{tabular}{cccccc}
\hline rater & sensitivity & specificity & ppv & npv & accuracy \\
\hline A & 0.77 & 0.58 & 0.28 & 0.92 & 0.61 \\
B & 0.77 & 0.53 & 0.25 & 0.92 & 0.57 \\
C & 0.86 & 0.33 & 0.21 & 0.92 & 0.42 \\
D & 0.87 & 0.39 & 0.24 & 0.93 & 0.48 \\
E & 0.78 & 0.57 & 0.29 & 0.92 & 0.61 \\
F & 0.83 & 0.31 & 0.20 & 0.90 & 0.40 \\
G & 0.68 & 0.75 & 0.36 & 0.92 & 0.74 \\
H & 0.69 & 0.38 & 0.19 & 0.86 & 0.44 \\
I & 0.91 & 0.43 & 0.25 & 0.96 & 0.51 \\
J & 0.75 & 0.58 & 0.27 & 0.92 & 0.61 \\
Panel $\varnothing$ & 0.85 & 0.69 & 0.37 & 0.96 & 0.72 \\
\hline
\end{tabular}



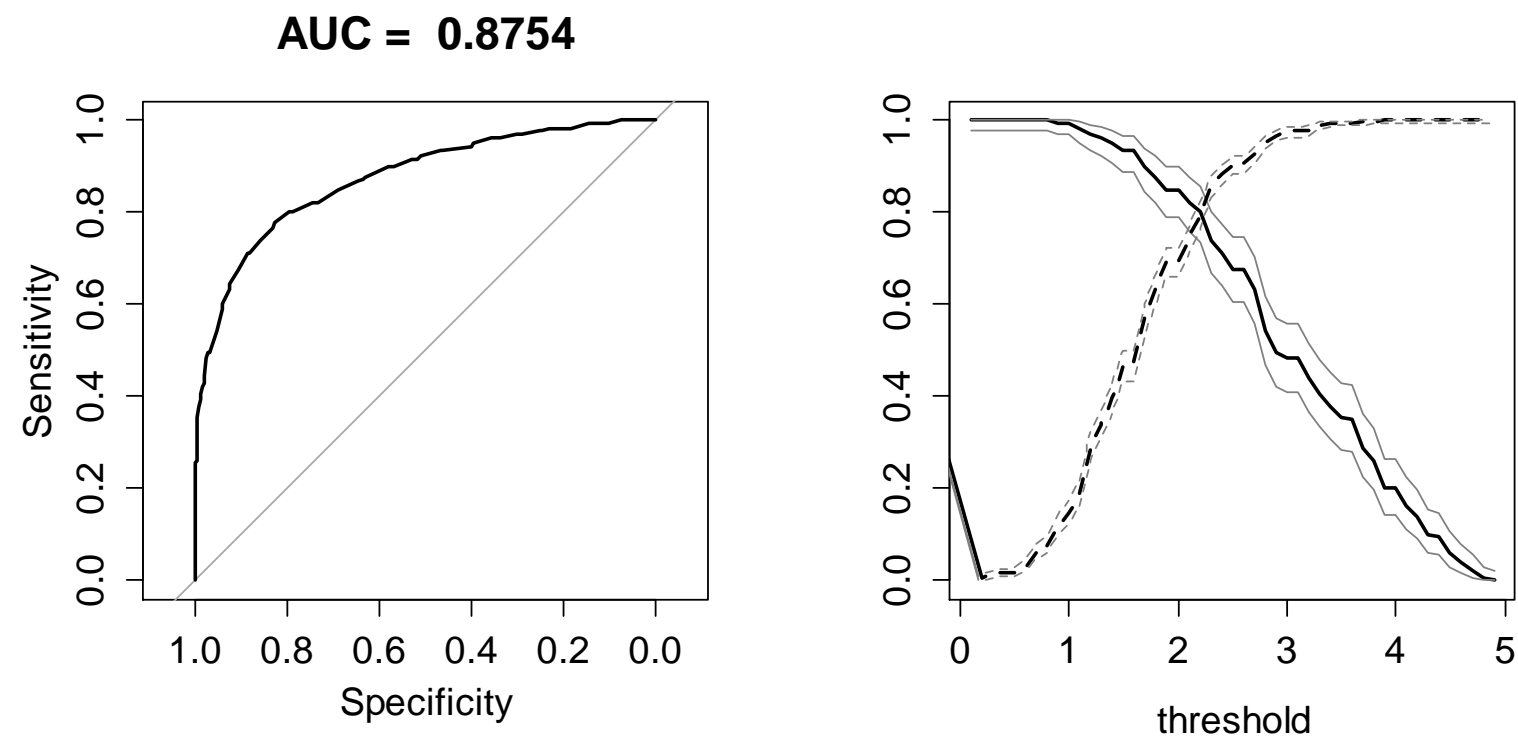

Supplement Figure 4. Performance of panel average as compared to chemical analysis: The left panel shows the ROC curve illustrating the sensitivity and specificity of the sensory evaluation for various sensory thresholds. The right panel shows the sensitivity (solid line) vs. specificity (dashed line) with respect to the chosen threshold for sensory classification of deviant smell. Chemical analysis was used as gold standard - a sample was considered as truly tainted if thresholds for androstenone (1.5 ppm) or skatole (0.2 ppm) were exceeded. 